\title{
6ạ Conferência Mundial de Pesquisa e Pós-Graduação em Turismo, Hospitalidade e Lazer e 2a Conferência Interdisciplinar de Pesquisa em Turismo
}

\section{6th World Conference for Graduate Research in Tourism, Hospitality and Leisure 2nd Interdisciplinary Tourism Research Conference}

\section{6a Conferencia Mundial de Investigación y Posgrado en Turismo, Hospitalidad y Ocio y 2a Conferencia Interdisciplinar de Investigación Turismo}

Fábia Trentin ${ }^{1}$

Carlos Alberto Lidizia Soares ${ }^{2}$

Bianca Tempone ${ }^{3}$

O presente texto constitui-se em um relato sobre os eventos 6a Conferência Mundial de Pesquisa de Pós-Graduação em Hotelaria, Turismo e Lazer e 2a Conferência de Pesquisa Interdisciplinar Turismo, realizados de 24 e 29 de abril de 2012 em Fethiye, na Turquia. Tratase de eventos organizados pelos professores de turismo Metin Kozak, da Mugla University, Turquia, e Nazmi Kozak, da Anadolu University, Turquia, e coeditores do periódico científico Anatolia - An International Journal of Tourism and Hospitality Research. Considera-se importante este relato no sentido de compartilhar o conteúdo dos eventos, bem como enfatizar suas contribuições para o campo do turismo, já que de início se destaca a baixa participação de pesquisadores brasileiros e da América do Sul como um todo.

Além de discutir a respeito do futuro da educação e pesquisa em turismo, as conferências abordaram temas como comportamento do consumidor, turismo sustentável, gestão do turismo, marketing turístico, informação e tecnologia no turismo e recreação e lazer.

A conferência de abertura intitulada "O futuro da educação e pesquisa em turismo:

\footnotetext{
${ }^{1}$ Doutoranda em Turismo, Lazer e Cultura. Professora do Departamento de Turismo da Universidade Federal Fluminense (UFF). Colaboradora do CEGOT/UC. E-mail: fabia@turismo.uff.br.

${ }^{2}$ Doutorando em Engenharia Civil. Professor do Departamento de Turismo da Universidade Federal Fluminense (UFF). E-mail: csoares@vm.uff.br.

${ }^{3}$ Doutoranda em Engenharia Civil Professora do Centro Federal de Educação Tecnológica. E-mail: biancatempone@gmail.com.
} 
oportunidades e mudança" foi proferida por Rich Perdue, da Virginia Tech, Estados Unidos, Jafar Jafari, University Wiscosin-Stout, Estados Unidos, Chris Ryan, University of Waikato, Nova Zelândia, Allan Fyall, Bournemouth University, Reino Unido. Na ocasião, os conferencistas destacaram a necessidade de estar atentos ao mundo contemporâneo sem perder o foco na formação dos profissionais de turismo e hospitalidade, o que, seguramente, representa um desafio para todos os países.

A conferência de encerramento com o tema "É o estudo do turismo Interdisciplinar ou está além das disciplinas?" proferida por John Urry, University of Lancaster, Reino Unido, Jafar Jafari, University of Wiscosin-Stout, Estados Unidos, Arch Woodside, Boston College, Estados Unidos, e Allan M. Williams, University of Surrey, Reino Unido, sugeriu que as disciplinas como são entendidas atualmente seguem padrões acadêmicos um tanto quanto conservadores. Pois, se houvesse uma abordagem focada no problema, ao invés de focar a disciplina, os estudos do turismo teriam um ganho significativo.

Os trabalhos estavam bem variados e foram distribuídos em sessões temáticas. Em termos de Brasil, não houve publicação de trabalhos nos anais da quarta e quinta edição da Conferência Mundial de Pesquisa de Pós-Graduação em Hotelaria, Turismo e Lazer, no entanto, nesta sexta edição, em 2012, um trabalho foi aceito e publicado nos anais. A 2a Conferência de Pesquisa Interdisciplinar Turismo segue a mesma tendência, com duas publicações de trabalhos de pesquisadores brasileiros.

De acordo com dados oficiais da organização do evento, foram submetidos 272 trabalhos por pesquisadores em distintas fases de sua carreira profissional, incluindo mestrandos e doutorandos. Vale informar que na estrutura da 6a Conferência Mundial de Pesquisa de Pós-Graduação em Hotelaria, Turismo e Lazer há espaço reservado para as apresentações de trabalhos em formato completo e pôster. Mais de 200 instituições de 50 países estavam representadas, possibilitando o contato com pesquisadores de vários países, sobretudo, da Ásia e do Oriente Médio.

Na 6ạ Conferência Mundial de Pesquisa de Pós-Graduação em Hotelaria, Turismo e Lazer foram apresentados 145 trabalhos. Deste total, 124 eram artigos de pesquisadores, 17 de estudantes de mestrado e quatro pôsteres. Os artigos concentraram-se essencialmente na temática de politica, planejamento e gestão do turismo nas mais diversas abordagens. Esse enfoque também marcou as abordagens presentes nos trabalhos que contemplaram os temas de hotéis e imagem, marcas e marketing em geral. O patrimônio e o turismo cultural, assim como turismo rural, turismo sustentável, turismo de eventos comportamento do consumidor, ecoturismo, turismo e gênero, tecnologia, inovação e informação, e educação estiveram entre as temáticas mais abordadas.

Outros temas menos explorados na conferência foram: backpackers, Gastronomia incluindo festival gastronômico, abordagens sobre os efeitos do turismo nos residentes; internet e agências de viagens; experiência do turista; mobilidade; turismo e mudança climática; enoturismo; investimentos em turismo; turismo e transporte; turismo e riscos; 
competitividade, responsabilidade social corporativa, entre outros.

Os trabalhos seguiram uma abordagem conservadora com poucas inovações temáticas acerca do turismo.

Do Brasil, a Universidade Federal Fluminense (UFF) foi representada na 6a Conferência Mundial de Pesquisa de Pós-Graduação em Hotelaria, Turismo e Lazer pela professora Fábia Trentin, e na 2a Conferência de Pesquisa Interdisciplinar de Turismo pelos professores Carlos Alberto Lidizia Soares e Orlando Longo. Bianca Tempone, do Centro Federal de Educação Tecnológica e Flávia Antunes Souza, Instituto Federal de Educação, Ciência e Tecnologia - RJ, respectivamente.

Finalmente, destaca-se que os trabalhos mais bem avaliados pela comissão científica foram premiados. E nesta edição da Conferência Mundial de Pesquisa de Pós-Graduação em Hotelaria Turismo e Lazer, os pesquisadores que ganharam os prêmios foram:

1. Charles Prêmio de Reconhecimento Goeldner - Abd Halim Norhazliza, da Universidade da Tasmânia, Austrália;

2. Award Outstanding PhD Dissertation - Nicole Arquivos-Thomspon, Howard University, Estados Unidos;

3. Prêmio Master de Outstanding Tese - Mohanna Nikbin, Islâmica Azad University, Irã; e

4. Prêmio Outstanding Paper Research - Cody Morris Paris, Middlesex University-Dubai, Emirados Árabes Unidos.

Por sua vez, na 2a Conferência de Pesquisa Interdisciplinar de Turismo, o Prêmio de Reconhecimento John Urry foi atribuído a Statia Elliot, da Universidade de Guelph, Canadá, a Nicolas Papadopoulos, Carleton University, Canadá; e a Leslie Szamosi, University of Sheffield, Reino Unido. 